\title{
Pesticide residues of fungicides applied in fruits and vegetables cultivated in Silesia and Opole provinces in 2011-2013
}

\author{
Pozostałości środków ochrony roślin z grupy fungicydów w owocach \\ i warzywach z terenów województw śląskiego i opolskiego \\ w latach 2011-2013
}

Klaudia Pszczolińska, Urszula Rzeszutko, Justyna Wlazło, Izabela Domańska

\begin{abstract}
Summary
In the years 2011-2013 308 samples of fruits and vegetables were examined under official control of testing pesticide residues in agricultural crops in The Laboratory of Pesticide Residue Research in Sośnicowice. The samples for testing were provided by the Provincial Inspectors State Plant Health and Seed Inspection in Katowice and Opole. Fifty-one active substances (authorized for usage) were detected in analyzed samples. The percentage of samples with residues of active substances in the Silesia province was $17.7 \%$ and $15.3 \%$ in Opole. One active substance of plant protection products prohibited for use in a given assortment was detected. Information notice was sent using the Rapid Alert System for Food and Feed (RASFF).
\end{abstract}

Key words: pesticide residue; fruit; vegetables; fungicide; south-west Poland

\section{Streszczenie}

W latach 2011-2013 w Laboratorium Badania Pozostałości Środków Ochrony Roślin w Sośnicowicach przebadano 308 próbek owoców i warzyw w ramach urzędowej kontroli badania pozostałości środków ochrony roślin w płodach rolnych. Próbki do badań dostarczane były przez Inspektorów Wojewódzkich Inspekcji Ochrony Roślin i Nasiennictwa w Katowicach i Opolu. W wyniku przeprowadzonych analiz w badanych próbkach wykryto 51 substancji czynnych (s.cz.) dopuszczonych do stosowania. Odsetek próbek z pozostałościami s.cz. wynosił w województwie śląskim 17,7\%, a w opolskim 15,3\%. Wykryto jedną s.cz. środka ochrony roślin niedozwoloną do stosowania w danym asortymencie. Informacja została przekazana w ramach systemu Rapid Alert System for Food and Feed (RASFF).

Słowa kluczowe: pozostałości środków ochrony roślin; owoce; warzywa; fungicydy; południowo-zachodnia Polska

Instytut Ochrony Roślin - Państwowy Instytut Badawczy

Oddział Sośnicowice

Laboratorium Badania Pozostałości Środków Ochrony Roślin

Gliwicka 29, 44-153 Sośnicowice

k.pszczolinska@ior.gliwice.pl 


\section{Wstęp / Introduction}

Pestycydy są niezbędnym elementem ochrony roślin. Według danych Głównego Urzędu Statystycznego (GUS), w strukturze sprzedaży środków ochrony roślin drugą, najczęściej sprzedawaną grupą, od roku 2008, są fungicydy czyli środki grzybobójcze (GUS 2012), mające szerokie zastosowanie w ochronie upraw sadowniczych i warzywniczych przed chorobotwórczymi patogenami. Związki te, oprócz korzystnego wpływu na produkcję roślinną, mogą stanowić źródło narażenia zdrowia ludzi (Biłyk i wsp. 2004; Makles i wsp. 2008). Owoce i warzywa sa podstawowym składnikiem naszej diety, dlatego przed ich wprowadzeniem do sprzedaży bardzo ważna staje się kontrola zawartości pozostałości środków ochrony roślin (ś.o.r.) i odniesienie uzyskanych wyników do obowiązujących norm - najwyższych dopuszczalnych pozostałości (NDP) (Rozporządzenie WE 2005).

Laboratorium Badania Pozostałości Środków Ochrony Roślin (LBPŚOR) Instytutu Ochrony Roślin - Państwowego Instytutu Badawczego (IOR - PIB) Oddział Sośnicowice prowadzi badania pozostałości ś.o.r. w ramach urzędowej kontroli płodów rolnych na lata 2011-2015, której celem jest ocena ewentualnych zanieczyszczeń pozostałościami ś.o.r., które mogą występować w plonach.

Celem pracy była ocena zanieczyszczeń pozostałościami ś.o.r. $\mathrm{z}$ grupy fungicydów $\mathrm{w}$ próbkach świeżych owoców i warzyw pobranych w latach 2011-2013, $\mathrm{z}$ terenu województwa śląskiego i opolskiego.

\section{Materiały i metody / Materials and methods}

Próby do badań pobierali losowo bezpośrednio z produkcji rolniczej (szklarni, tuneli foliowych, gruntu, sadów) lub pomieszczeń magazynowych, Inspektorzy Wojewódzkich Inspekcji Ochrony Roślin i Nasiennictwa (WIORiN) w Katowicach i Opolu zgodnie z programem kontroli urzędowej dla poszczególnych upraw. Do LBPŚOR dostarczono 119 prób owoców i 189 warzyw. Program badań obejmował oznaczenie 56 substancji czynnych (s.cz.) w roku 2011, 61 s.cz. w roku 2012 i o kolejne 5 s.cz. więcej w roku 2013 (tab. 1).

Do oznaczeń pozostałości s.cz. stosowano metody wielopozostałościowe umożliwiające wykrycie wielu związków w jednym toku analitycznym, zgodnie z obowiązującymi normami (SANCO 2011). Poprawność metod sprawdzono przez udział $w$ międzylaboratoryjnych badaniach biegłości organizowanych przez The Food Analysis Performance Assessment Schame (FAPAS) oraz Unię Europejską (European Comission's Proficience Test on Pesticide Residues in Fruit and Vegetables). Laboratorium uzyskało poprawne wyniki potwierdzając tym samym biegłość techniczną $\mathrm{w}$ realizowanym zakresie badań.

W procesie ekstrakcji próbek środowiskowych zastosowano technikę rozpraszania matrycy na fazie stałej MSPD (matrix solid phase dispersion) (Kadeneczki i wsp. 1992). W zależności od asortymentu, część próbek była poddana dodatkowo oczyszczeniu na kolumienkach SPE (Solid-Phase Extraction), wypełnionych żelem krzemionkowym $(0,5 \mathrm{~g})$. W roku 2013 próby analizowano również metodą opartą na technice QuEChERS (Quick, Easy, Cheap, Effective, Rugged and Safe) (Anastassiades i wsp. 2003). Oznaczenia ilościowe i jakościowe wykonano na chromatografie gazowym Agilent 7890A, wyposażonym $\mathrm{w}$ detektory selektywne $\mu \mathrm{EC}$ (wychwytu elektronów) i NPD (azotowo-fosforowy) oraz kolumnę 5 MS UI. Jakościowe potwierdzenie uzyskanych wyników wykonano na chromatografie gazowym Agilent 7890A wyposażonym w detektor masowy. Pozostałości ditiokarbaminianów wyrażone jako $\mathrm{CS}_{2}$ oznaczono spektrofotometrycznie (Chmiel 1979).

\section{Wyniki i dyskusja / Results and discussion}

Pozostałości ś.o.r. $\mathrm{z}$ grupy fungicydów stwierdzono w 51 przypadkach, co stanowi 16,5\% ogółu analizowanych prób. Odsetek próbek z pozostałościami s.cz. wynosił w województwie śląskim 17,7\%, a w opolskim 15,3\%. Pozostałości s.cz. częściej wykrywano w owocach $(31,9 \%)$ niż w warzywach $(6,9 \%)$ mimo, że liczba badanych prób owoców była mniejsza niż warzyw. Wyniki te korelują $\mathrm{z}$ wynikami otrzymanymi $\mathrm{w}$ monitoringu krajowym $\mathrm{z}$ lat 2010-2011 (Nowacka i wsp. 2011, 2012b).

Najczęściej wykrywanymi fungicydami były ditiokarbaminiany (18 próbek) oraz boskalid (16 próbek) (tab. 2). Największy odsetek prób zawierających fungicydy ditiokarbaminianowe oznaczano również na terenie innych województw w latach 2008-2012 (Łozowicka i wsp. 2012; Nowacka i wsp. 2012a; Szpyrka i wsp. 2013). Pozostałości ditiokarbaminianów najczęściej wykrywano w truskawkach, w których są stosowane do zwalczania szarej pleśni, częstej choroby wywołanej przez grzyba Botrytis cinerea (Zalecenia ochrony roślin 2010/2011, 2012/2013).

Tabela 1. Analizowane substancje czynne (2011-2013)

Table 1. Analyzed active substances (2011-2013)

Substancje czynne - Active substances

azaconazole, azoxystrobin, benalaxyl, bitertanol, boscalid, bromuconazole, bupirimate, captan, chlorothalonil, cyproconazole, cyprodinil, dichlofluanid, dicloran, difenoconazole, dimethomorph, dimoxystrobin, diniconazole, diphenylamine, dithiocarbamates, epoxiconazole, fenarimol, fenbuconazole, fenhexamid, fenpropimorph, fludioxonil, flutolanil ${ }^{2}$, fluopicolide ${ }^{2}$, fluquinconazole, flusilazole, flutriafol, folpet, hexachlorobenzene, hexaconazole ${ }^{1}$, imazalil, imibenconazole, iprodione, krezoxim-methyl, mepanipyrim, metalaxyl, metconazole ${ }^{1}$, metrafenone ${ }^{2}$, myclobutanil, oxadixyl, penconazole, pencycuron ${ }^{1}$, picoxystrobin, prochloraz, procymidone, propiconazole, prothioconazole ${ }^{2}$, pyrazophos, pyrimethanil, quinoxyfen, quintozene, spiroxamine ${ }^{1}$, tebuconazole, tecnazene, tetraconazole, tolclofos-methyl, tolylfluanid, triadimefon, triadimenol, trifloxystrobin, triticonazole ${ }^{2}$, vinclozolin, zoxamide ${ }^{1}$

\footnotetext{
${ }^{1}$ substancje czynne włączone do programu badań od 2012 roku - substances included in the analysis program since 2012
}

${ }^{2}$ substancje czynne włączone do programu badań od 2013 roku - substances included in the analysis program since 2013 
Tabela 2. Pozostałości substancji czynnych środków ochrony roślin w owocach i warzywach

Table 2. Residues of active substances detected in fruits and vegetables

\begin{tabular}{|c|c|c|c|c|c|c|c|c|c|}
\hline \multirow{3}{*}{$\begin{array}{l}\text { Klasyfikacja } \\
\text { Classification }\end{array}$} & \multirow{3}{*}{$\begin{array}{l}\text { Produkt } \\
\text { Product }\end{array}$} & \multicolumn{3}{|c|}{$\begin{array}{l}\text { Liczba próbek } \\
\text { Number of samples }\end{array}$} & \multicolumn{4}{|c|}{$\begin{array}{l}\text { Próbki z pozostałościami } \\
\text { Samples with residues }\end{array}$} & \multirow{3}{*}{$\begin{array}{c}\text { Wartość lub zakres } \\
\text { wykrytych pozostałości } \\
\text { Value or range } \\
\text { of detected residues } \\
{[\mathrm{mg} / \mathrm{kg}]}\end{array}$} \\
\hline & & \multirow[t]{2}{*}{2011} & \multirow[t]{2}{*}{2012} & \multirow[t]{2}{*}{2013} & \multirow{2}{*}{$\begin{array}{l}\text { substancja czynna } \\
\text { active substance }\end{array}$} & \multicolumn{3}{|c|}{$\begin{array}{c}\text { liczba próbek } \\
\text { number of samples }\end{array}$} & \\
\hline & & & & & & 2011 & 2012 & 2013 & \\
\hline \multirow{7}{*}{$\begin{array}{l}\text { Owoce } \\
\text { Fruits }\end{array}$} & $\begin{array}{l}\text { borówka } \\
\text { blueberry }\end{array}$ & - & 2 & - & $\begin{array}{c}\text { dithiocarbamates } \\
\text { cyprodinil } \\
\text { fludioxonil }\end{array}$ & $\begin{array}{l}- \\
- \\
-\end{array}$ & $\begin{array}{l}1 \\
1 \\
1\end{array}$ & $\begin{array}{l}- \\
- \\
-\end{array}$ & $\begin{array}{c}0,23 \\
0,09 \\
0,1\end{array}$ \\
\hline & $\begin{array}{l}\text { jabłko } \\
\text { apple }\end{array}$ & 2 & 9 & 20 & $\begin{array}{c}\text { trifloxystrobin } \\
\text { dithiocarbamates } \\
\text { captan }\end{array}$ & $\begin{array}{l}- \\
- \\
-\end{array}$ & $\begin{array}{l}1 \\
- \\
-\end{array}$ & $\begin{array}{l}1 \\
3 \\
3\end{array}$ & $\begin{array}{l}0,04-0,11 \\
0,07-0,29 \\
0,05-1,69\end{array}$ \\
\hline & $\begin{array}{l}\text { malina } \\
\text { rasberry }\end{array}$ & 1 & 4 & 7 & $\begin{array}{c}\text { boscaild } \\
\text { cyprodinil } \\
\text { fludioxonil } \\
\text { pyrimethanil }\end{array}$ & $\begin{array}{l}1 \\
1 \\
1 \\
1\end{array}$ & $\begin{array}{l}- \\
- \\
- \\
-\end{array}$ & $\begin{array}{l}1 \\
1 \\
1 \\
-\end{array}$ & $\begin{array}{c}1,05-1,14 \\
0,31-1,02 \\
0,23-0,49 \\
0,33\end{array}$ \\
\hline & $\begin{array}{l}\text { porzeczka } \\
\text { currant }\end{array}$ & - & 6 & 9 & dithiocarbamates & - & 1 & 1 & $0,86-2,2$ \\
\hline & $\begin{array}{l}\text { truskawka } \\
\text { strawberry }\end{array}$ & - & 29 & 7 & $\begin{array}{l}\text { dithiocarbamates } \\
\text { trifloxystrobin } \\
\text { boscaild } \\
\text { fludioxonil } \\
\text { cyprodinil } \\
\text { pyrimethanil } \\
\text { tetraconazole }\end{array}$ & $\begin{array}{l}- \\
- \\
- \\
- \\
- \\
- \\
-\end{array}$ & $\begin{array}{c}7 \\
2 \\
11 \\
4 \\
4 \\
- \\
-\end{array}$ & $\begin{array}{l}3 \\
- \\
3 \\
1 \\
- \\
1 \\
1\end{array}$ & $\begin{array}{c}0,05-0,75 \\
0,13 \\
0,02-1,1 \\
0,02-0,11 \\
0,05-0,21 \\
0,09 \\
0,03\end{array}$ \\
\hline & $\begin{array}{l}\text { gruszka } \\
\text { pear }\end{array}$ & - & 2 & 4 & captan & - & - & 2 & $0,2-0,44$ \\
\hline & $\begin{array}{l}\text { winogrona } \\
\text { grapes }\end{array}$ & - & 2 & 1 & dithiocarbamates & - & - & 1 & 0,15 \\
\hline \multirow{7}{*}{$\begin{array}{l}\text { Warzywa } \\
\text { Vegetables }\end{array}$} & $\begin{array}{l}\text { marchew } \\
\text { carrot }\end{array}$ & 7 & 3 & 2 & propiconazole & 1 & - & - & 0,07 \\
\hline & $\begin{array}{l}\text { pomidor } \\
\text { tomato }\end{array}$ & 2 & 18 & 9 & $\begin{array}{l}\text { chlorothalonil } \\
\text { iprodione } \\
\text { dithiocarbamates } \\
\text { azoxystrobin }\end{array}$ & $\begin{array}{l}- \\
- \\
- \\
-\end{array}$ & $\begin{array}{l}3 \\
1 \\
1 \\
-\end{array}$ & $\begin{array}{l}- \\
- \\
- \\
1\end{array}$ & $\begin{array}{c}0,21-0,65 \\
0,33 \\
0,1 \\
0,06\end{array}$ \\
\hline & $\begin{array}{l}\text { ogórek } \\
\text { cucumber }\end{array}$ & 0 & 17 & 6 & $\begin{array}{l}\text { azoxystrobin } \\
\text { metalaxyl }\end{array}$ & $\begin{array}{l}- \\
-\end{array}$ & $\begin{array}{l}- \\
-\end{array}$ & $\begin{array}{l}1 \\
1\end{array}$ & $\begin{array}{l}0,11 \\
0,02\end{array}$ \\
\hline & $\begin{array}{l}\text { pietruszka } \\
\text { korzeń } \\
\text { parsley root }\end{array}$ & 4 & 12 & 0 & azoxystrobin & - & 1 & - & 0,05 \\
\hline & $\begin{array}{l}\text { seler } \\
\text { celery }\end{array}$ & 1 & 1 & 1 & azoxystrobin & - & 1 & - & 0,08 \\
\hline & $\begin{array}{l}\text { sałata } \\
\text { lettuce }\end{array}$ & 0 & 4 & 3 & azoxystrobin & - & - & 1 & 2,95 \\
\hline & $\begin{array}{l}\text { kapusta } \\
\text { cabbage }\end{array}$ & 6 & 0 & 3 & azoxystrobin & - & - & 1 & 0,08 \\
\hline
\end{tabular}

W badanych próbkach stwierdzono obecność pozostałości wielokrotnych. W 13 próbkach odnotowano więcej niż jedną pozostałość s.cz. Najwyższy odsetek stanowiły próbki, w których obecne były dwie s.cz. (11,8\%) (rys. 1). Najczęściej pojawiającym się zestawieniem s.cz. (4 próbki) to: boskalid i ditiokarbaminiany.

W żadnej badanej próbie nie wykryto pozostałości s.cz. przekraczających NDP, jednakże wykryto zastosowanie niedozwolonego ś.o.r. (Ustawa 2003; Ustawa 2013) zawierającego azoksystrobinę $\mathrm{w}$ uprawie ogórka. Ponadto producent uprawy ogórka nie zgłosił podczas pobrania próby zastosowania środka zawierającego azoksystrobinę. Informacja została przekazana w ramach systemu Rapid Alert System for Food and Feed (RASFF) (Ustawa 2006). W podanym okresie badań na terenie Polski również wykryto przypadki zastosowania preparatu zawierającego 
azoksystrobinę niezgodnie z zaleceniami (Nowacka i wsp. 2012a; Łozowicka i wsp. 2012).

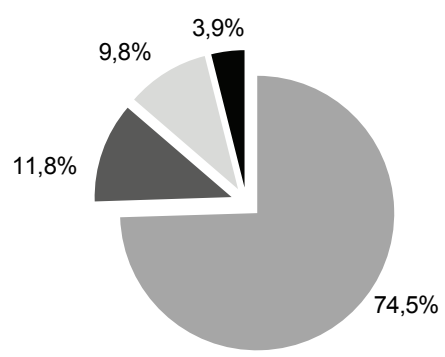

- Próbki z pozostałością 1 s.cz. - Samples with 1 active substance

-Próbki z pozostałością 2 s.cz. - Samples with 2 active substances

Próbki z pozostałością 3 s.cz. - Samples with 3 active substances

-Próbki z pozostałością 4 s.cz. - Samples with 4 active substances

Rys. 1. Próbki z wielokrotnymi pozostałościami

Fig. 1. Samples with pesticide multiresidue

W większości analizowanych próbek, tj. 83,5\%, nie wykryto pozostałości, powyżej granic oznaczalności metody analitycznej. Pozostałości s.cz. nie stwierdzono w takim asortymencie, jak: czereśnia ( 3 - liczba badanych próbek), wiśnia (5), śliwa (3), brzoskwinia (2), agrest (1), burak ćwikłowy (21), burak cukrowy (10), ziemniak (24), papryka (9), kalafior (3), fasolka szparagowa (2), rzodkiewka (1), cebula (5), kapusta pekińska (4), por (8), groszek (1), bób (2).

\section{Wnioski / Conclusions}

1. Na podstawie analizy 308 próbek owoców i warzyw $\mathrm{z}$ terenu województwa opolskiego i śląskiego największy udział próbek z pozostałościami stwierdzono w owocach (31,9\%), mimo że stanowiły tylko 38,6\% ogółu badanych prób.

2. Fungicydy $\mathrm{z}$ grupy ditiokarbaminianów były najczęściej wykrywanymi s.cz.

3. Nieprawidłowości związane ze stosowaniem ś.o.r. dotyczyły wyłącznie zastosowania niedozwolonego ś.o.r. do ochrony danej uprawy.

4. W 83,5\% analizowanych próbek nie stwierdzono wykrywalnych pozostałości s.cz. badanych ś.o.r.

\section{Literatura / References}

Anastassiades M., Lehotay S., Stajnbaher D., Schneck F.J. 2003. Fast and easy multiresidue method employing acetonitrile extraction/partitioning and "dispersive solid-phase ectraction" for the determination of pesticide residues in produce. J. AOAC Int. 86: $412-431$.

Biłyk A., Nowak-Piechota G. 2004. Zanieczyszczenia środowiska substancjami powodującymi zakłócenia funkcji endokronologicznych organizmu. Ochrona Środowiska 3: 29-35.

Chmiel Z. 1979. Spektrofotometryczne oznaczanie śladowych pozostałości dwuditiokarbaminianów w materiale roślinnym. Chem. Anal. 24: 505-511.

GUS 2012. Środki produkcji w rolnictwie w roku gospodarczym 2011/2012. Warszawa, 46 ss.

Kadeneczki L., Arpad Z., Gardi I., Ambrus A., Gyorfi L., Reese G., Ebing W. 1992. Column extraction of residues of severa; pesticides from fruits and vegetables: A simple multiresidue analysis method. J. AOAC Int. 75: 53-61.

Łozowicka B., Hrynko I., Rutkowska E., Jankowska M., Kaczyński P., Janowicz T. 2012. Pozostałości środków ochrony roślin w owocach i warzywach z północno-wschodniej Polski (2008-2011). [Pesticide residues in fruit and vegetables from north-eastern Poland (2008-20110)]. Prog. Plant Prot./Post. Ochr. Roślin 52 (2): 423-430.

Makles Z., Domański W. 2008. Ślady pestycydów - niebezpieczne dla człowieka i środowiska. Bezpieczeństwo Pracy 1: 5-9.

Nowacka A., Gnusowski B., Walorczyk S., Drożdżyński S., Raczkowski M., Hołodyńska A., Frąckowiak D., Wójcik A., Ziółkowski A., Rzeszutko U., Domańska I., Jurys J., Łozowicka B., Kaczyński P., Rutkowska E., Jankowska M., Hrynko I., Szpyrka E., Rupar J., Rogozińska K., Kurdziel A., Słowik-Borowiec M., Michel M., Kuźmenko A., Szala J. 2011. Pozostałości środków ochrony roślin w płodach rolnych (rok 2010). [Pesticide residues in polish crops]. Prog. Plant Prot./Post. Ochr. Roślin 51 (4): 1723-1738.

Nowacka A., Gnusowski B., Walorczyk S., Drożdżyński S., Raczkowski M., Hołodyńska A., Frąckowiak D., Swoboda W. 2012a. Pozostałości środków ochrony roślin w płodach rolnych wyprodukowanych w północno-zachodniej Polsce. [Pesticide residues in crops produced in north-western Poland]. Prog. Plant Prot./Post. Ochr. Roślin 52 (4): 1101-1105.

Nowacka A., Gnusowski B., Walorczyk S., Drożdżyński S., Raczkowski M., Hołodyńska A., Frąckowiak D., Wójcik A., Ziółkowski A., Przewoźniak M., Swoboda W., Rzeszutko U., Domańska I., Jurys J., Łozowicka B., Kaczyński P., Rutkowska E., Jankowska M., Hrynko I., Szpyrka E., Rupar J., Rogozińska K., Kurdziel A., Słowik-Borowiec M., Szala J., Szponik M., Michel M. $2012 b$. Pozostałości środków ochrony roślin w płodach rolnych (rok 2011). [Pesticide residues in Polish crops (2011)]. Prog. Plant Prot./Post. Ochr. Roślin 52 (4): 1106-1116.

Rozporządzenie (WE) nr 396/2005 Parlamentu Europejskiego i Rady Europy z dnia 23 lutego 2005 roku z późn. zm. w sprawie najwyższych dopuszczalnych poziomów pozostałości pestycydów w żywności i paszy pochodzenia roślinnego i zwierzęcego oraz na ich powierzchni, zmieniające dyrektywę Rady 91/414/EWG (Dz. U. L 70, str. 1 z 16.03.2005., z późn. zm.).

SANCO/12495/2011. 2011. Method validation and quality control procedures for pesticide residues analysis in food end feed, $40 \mathrm{pp}$.

Szpyrka E., Kurdziel A., Matyaszek A., Podbielska M., Rupar J., Słowik-Borowiec M. 2013. Pozostałości środków ochrony roślin w płodach rolnych z terenu południowo-wschodniej Polski (rok 2012). [Pesticide residues in crops from the south-eastern region of Poland (2012)]. Prog. Plant Prot./Post. Ochr. Roślin 53 (2): 402-406.

Ustawa z dnia 18 grudnia 2003 r. o ochronie roślin. 2004. Dz. U. Nr 11, poz. 94, z późn. zm.

Ustawa z dnia 25 sierpnia 2006 r. o bezpieczeństwie żywności i żywienia. Dz. U. Nr 171, poz. 1225, z późn. zm.

Ustawa z dnia 08 marca 2013 r. o środkach ochrony roślin. 2013. Dz. U. 2013, poz. 455, z późn. zm.

Zalecenia ochrony roślin na lata 2010/2011. Cz. III. Warzywa, Sady. Inst. Ochr. Roślin - PIB, Poznań, 228 ss.

Zalecenia ochrony roślin na lata 2012/2013. Cz. III. Warzywa, Sady. Inst. Ochr. Roślin - PIB, Poznań, 219 ss. 